\title{
6.6 Sociocultural competences as essential components in teaching English
}

The new social demands of modern society are focused on teaching foreign languages as a means of cross-cultural communication, the formation of a person ready for interethnic communication, and are reflected in the cultural policy of the Council of Europe and in the concepts of intercultural and sociolinguistic teaching of philological subjects. One of the priorities of English language teaching is the formation of students' sociolinguistic competence, which requires knowledge of national and cultural features of English-speaking countries, the norms of speech and non-speech behaviour of its speakers, and the ability to build their behaviour following these features and norms. Therefore, the purpose of the present study is to reveal the ways of forming students' sociolinguistic competence as a component of the process of teaching English, which is the key to effective cross-cultural communication.

Recent years have revealed a trend of increasing attention of scientists to the phenomenon of sociolinguistic competence as one of the indicators of a person's readiness for intercultural communication. The problem of the formation of sociolinguistic competence in the process of learning foreign languages is widely discussed, because the formation of sociolinguistic competences involves penetration into the culture, into the system of worldview and comprehension of the people. Since language and literature are forms of human mental activity, they cover all spheres of individual and social life, they constitute a part of human nature and reveal practical and theoretical activities of both an individual and a society [437]. The problem of the formation of sociolinguistic competence in the process of learning foreign languages has been dealt with by domestic and foreign linguists, namely by O. V. Ter-Minasova,
O. A. Kanibolotskaya,
G. V. Kolshansky,
T. V. Romanova,
O. D. Schweizer,

O. O. Pershukova, N. D. Galkova, E. Sapir, the research results of which were used in writing the present article.

The issue of acculturation is directly related to the teaching of English: the only and maximum purpose of teaching culture in connection with language and literature is the formation of a personality at the crossroads of cultures. In close connection with 
this problem, there is another set of methodological issues, namely the sociolinguistic aspect of teaching English. The social nature and essence of language should be understood as the unity of language and culture, the unity of language and society. Without a doubt, language and culture are interconnected. It is generally accepted that cultural processes affect language and language affects culture. If the influence of culture on language is obvious, then the influence of language on culture is not subject to ordinary observation. This problem was raised by W. von Humboldt, followed by E. Sapir and B. Wharf. But their hypothesis of linguistic relativity has not been conclusively proven by anyone. Other interesting opinions were expressed, for example, that certain types of culture determine certain language structures. However, these theories remained at the level of hypotheses.

George Peter M. [438, p. 124] defines the term culture as the set of values, customs, beliefs, and practices that constitute the way of life of a specific group, to start from a deeper knowledge. Likewise, the definition and etymology of this term by Terry Eagleton [439, p.58], indicates that the term culture has been created by the use of symbols. Etymologically this term is derived from the Latin word colere used to express "the tillage and use of the land" referring this meaning to cultivation, agriculture, cultivating the land. On the other hand, the Romans referred to the term cultura animi as the cultivation of the soul. The main thing that the term culture contributes is that values, customs, and practices constitute the way of life of every society. The term culture is more identified in this work with a special mention of languages, since this is an identity of society and even more so in learning a foreign language, considering that it varies from region to region. So, studying a language also implies learning that part of the values and customs that are part of the target language, and of a certain community, such is the case of the English language that contains a varied power and wide culture, of which we must be part when learning this language.

According to E. Sapir, "culture can be defined as what society does and thinks. Language is what people think. It is difficult to determine what special causal relationships can be expected between the selected inventory of experience (culture as a value choice of society) and the special technique by which society expresses its 
various experiences $[\ldots]$. The content of language is inextricably linked with the culture $[\ldots]$. Language through its vocabulary more or less accurately reflects the culture it does not serve; it is quite fair that the history of language and the history of culture develop in parallel [440, p. 171 - 172].

In academia, the teaching of culture has traditionally taken place separately from language and has often been restricted to the study of history, the political system, institutions, and folklore which constituted the Culture starting with a capital letter. Without considering cultural aspects as relevant to communication as presuppositions, misunderstandings, opinions and beliefs, and behaviour patterns (culture, starting with a lowercase letter) that openly determine communicative interaction within a given speech community.

The sociocultural component linked to language learning plays a central role in guaranteeing an effective communicative exchange. However, when introducing these contents in the classroom, the problem arises of what to teach at each level or how to do it without falling into stereotyping or clichés. In such a way that the information offered to the students is adapted to their training, their tastes, and interests and that it corresponds to the level of linguistic knowledge they possess, as well as that the cultural contents are contextualized and related to what the students already know. However, this process is not always straightforward. One of the examples that S. Pastor Cesteros cites regarding the relationship between language and culture is a reference to the speech acts: "the speech acts of some languages do not coincide with those of others, or they do not exist, or they develop differently" [441, p. 140]. This phenomenon has been widely studied in the Anglo-Saxon field, giving rise to a multitude of works on intercultural pragmatics that address how various speech acts are carried out such as complaining, expressing gratitude, apologizing, making requests, invitations, suggestions, taking the turn in the conversation, interrupt, etc. These contrastive studies referred to certain differences between the uses of English by representatives of Eastern and Western cultures, with a special emphasis on different pragmatics. 
Communicative speech competence consists of certain components: linguistic, sociolinguistic, and pragmatic. Each of these components includes, in particular, knowledge, skills, and abilities. Linguistic competencies include lexical, phonological, syntactic knowledge and skills, and other parameters of language as a system, regardless of the pragmatic functions of their implementation [442]. Sociolinguistic competence refers to the sociocultural conditions of language use. Due to the sensitivity to social conventions (rules of politeness, norms governing relations between generations, classes and social groups, linguistic codifications of some basic rituals in society), the sociolinguistic component permeates the entire process of communication between different cultures, even when its participants often are not aware of this impact.

Pragmatics deals with the textual conditions in which the linguistic events described by syntax and semantics take place; that is, according to M. López García, the use of the language in its context, as well as the extralinguistic aspects [443, p. 3839]. This discipline, in addition to being a theory of linguistic communication, studies how the speakers of a certain language interpret sentences within a context, that is, how they analyse the language in use since it is always contextualized. It is a discipline that is closely related to the teaching of foreign languages because it is important to convey to students that in each culture, in most cases, the speakers say not only what they mean but they also choose to say what is expected to be said. This is essential because linguistic expression is well codified by social norms that tell us how to behave appropriately in a group; obviously, the cultures of Ukraine and that of the UK or the United States are very different in this sense. Linguistic behaviour in the act of communication is one of the priorities since the existence of misunderstandings or misinterpretations within communication is more frequent in learning foreign languages than in communication in the native language. In the sense of the cultural and contextual aspects, the student needs to be aware of the fact that the behaviour of a speaker in each culture differs depending on the society. Therefore, it should be taken into account that if misinterpretations frequently occur in the mother tongue, yet are there more problems in the communication in the foreign language. For this reason, 
learning a foreign language is not just about acquiring skills of the correct and appropriate use of grammar and vocabulary, on the contrary, it goes beyond these aspects leading to the acquisition of different non-linguistic competences.

Pragmatic competencies are related to the functional use of linguistic means: the production of language functions, acts of speech, etc. They offer scripts or programs of an interactive exchange. They also deal with the skills of discourse, fusion, and coherence, identification of types and forms of texts, irony, and parody. For this component to function, it is essential to emphasize the importance of the interactions and cultural visions in which abilities are formed, even more than the value of the linguistic component.

Sociocultural competence (which includes sociolinguistic competence) involves expanding knowledge of sociocultural specifics of countries, improving the ability to build their language and non-verbal behaviour in accordance with this specificity, and taking into account the social status of communication partners, the ability to adequately understand and interpret. It is planned to expand the scope of linguistic and regional knowledge, skills, and abilities due to new topics and issues of language communication, taking into account the specifics of the educational profile: deepening knowledge about the country of the studied language, its culture, historical and modern realities, public figures, its place in the world community, culture, relations with other countries; expanding the amount of linguistic and cultural knowledge, skills, and abilities associated with the adequate use of language tools and rules of language and non-language behaviour in accordance with the sphere of communication, place, goals, social status of the interlocutor.

Sociolinguistic competences refer to the sociocultural conditions of the use of the language. Through its sensitivity to social conventions, the norms of courtesy, the norms that order relations between generations, sexes, classes, and social groups, the linguistic codification of certain fundamental rituals for the functioning of a community, the sociolinguistic component considerably affects the entire community by shaping the result of linguistic communication between representatives of different 
cultures, although the members involved in the action of communication may often not be aware of their influence.

Currently, the sociocultural component of learning is integrated into communicative competence, giving priority to the needs of the student when facing cultural difficulties that may arise in the daily life of a foreign country, or at the time of communication between Ukrainian students and native English speakers. The English language that is taught as a foreign language in countries other than the English-speaking ones may be lacking in cultural aspects because of high chances of impossibility, for example, to go to do internships in the countries where this language is official in order to soak up cultural knowledge. Neither is there a frequent special emphasis given to the teaching of the target culture, as it should be done together with the teaching of the target language. Thus, the formation of English-language communicative competence of students is impossible without achieving sociocultural competence, which includes regional and linguistic competence. Local lore competence provides students with knowledge of history, geography, economics, socio-political system, culture, life, traditions of Great Britain, USA, Canada, Australia, and other countries the official language of which is English. And linguistic competence is to develop speech and non-speech skills (facial expressions, gestures that accompany utterances) behaviour of native English speakers in certain communicative situations. This allows students to form a holistic system of ideas about the speech and national and cultural features of English-speaking countries and in this way to achieve full productivity in communication.

The separate view of linguistic competence as an integral part of the study of English is because the language itself as a means of communication tends to accumulate, store and reflect the facts and events of historical and cultural development of the native people of this language. These facts and phenomena are known, as a rule, to all members of a certain linguistic community, as they are assimilated by them in the process of education, training, etc. For example, the people of London are well aware of the meaning of the word the tube - London Underground transport system; the name of a street in London - Whitehall - can be used by the British people to mean 
the UK government. The main street of many cities in the UK is called the High Street; the abbreviation Oxbridge (Oxford + Cambridge) is often used. Americans are well aware that cheap consumer goods are sold in cent stores or Woolworth stores, and that sneakers are rubber-soled shoes or sport shoes. Australian English contains a large number of lexical items that are not used in the literary language, or have a special meaning. As a result, when students are introduced to such vocabulary additional sociolinguistic commentary is required. For example, durry - cigarette; pineapple - a fifty dollar note; spud - potato; manchester - household linen; OYO - on your own (flat or apartment); parcel - package; tea - evening meal; paddock - field, meadow. The word hotel gets the additional connotative meaning of "bar, pub" and is used instead of the normative English term $p u b$. In the Sydney area, the pejorative word brad is used to refer to immigrants from Southeast Asia. Abbreviations are common in the Australian national variant of English: ute - utility vehicle; cossie - swimming costume. Australians use the term rockmelon to refer to a variety of melon (the common scientific name is Cucumis melo cantalupensis), and in the province of Victoria, the word cantaloupe is used, which is also common to the American national variant of the English language. There are different lexical tokens to denote different varieties of dried grapes in the Australian variant, for example, sultanas, currants, the common hyperonym being raisins. Typical Australian realia, i.e., lexical units representing local realities, are didjeridu - a cylindrical musical instrument played by aboriginals; bat house - a house made of sun-dried bricks; boudy rat-marsupial devil, a small animal; brumby - a wild, untamed horse; costeen - a small pit in the upper layer of earth to access the gold-bearing formation; mallee - a species of Australian acacia; mulga - a species of eucalyptus. The above-mentioned realities reflect the specifics of a respective English-speaking society and national colour. Therefore, Anglicisms, Americanisms, Australianisms, etc. are lexical units that mean objects or phenomena that are characteristic of the British, American, Australian version of English. For example, the words ranch, prairie, drugstore are common in American English and express concepts of American society. 
Semantically, realities can be categorized into classes according to the lexical and semantic field they belong to. Geographical realities are related to physical geography and include the names of both natural and man-made objects, e.g.: Golden Gate Bridge, one of the largest bridges in the United States located in the San Francisco area; Underground Atlanta is a complex of shops, clubs, and restaurants; Fisherman's Wharf is a fishing spot, a stretch of the San Francisco Bay waterfront that is one of the landmarks of the city of San Francisco. On the other hand, ethnographic realities include words denoting the concepts of life, material and spiritual culture, religion, art, folklore, e.g.: Tooth fairy - a fantasy figure of early childhood in Western and Westerninfluenced cultures; the folklore states that when children lose one of their baby teeth, they should place it underneath their pillow or on their bedside table and the Tooth Fairy will visit while they sleep, replacing the lost tooth with a small payment; Easter bunny (also called the Easter Rabbit or Easter Hare) is a folkloric figure and symbol of Easter, depicted as a rabbit, sometimes dressed in clothes, bringing Easter eggs; Broadway is a famous street in New York City with theatres; sweatshirt is a type of sweater. Socio-political realities are a fairly broad category, which includes vocabulary to denote the administrative and territorial structure, bodies and holders of power, phenomena of socio-political life, e.g.: the Congress - the bicameral legislature of the federal government of the United States consisting of the House of Representatives and the Senate and located in Washington, DC, the Supreme Court of the United States the highest court in the federal judiciary of the United States of America; the Penitentiary - a correctional facility, a federal prison for convicted criminals.

To be effective in intercultural communication, these semantic divergences should be taken into account during communication, as neglect of this background knowledge leads to frustration of the communicative act. Such information refers to the background knowledge possessed by the inhabitants of a particular country, but in many cases, it is unknown to foreigners, which greatly complicates the communication process. Linguistic means of realization of background knowledge are the realia (nonequivalent lexical units, abbreviations, names of historical events and names of historical figures, names of phenomena of social and cultural life of the country) and 
background vocabulary (foreign vocabulary that differs in its lexical background from native language vocabulary). Thus, the literal translation of the name of London's Downing Street is not exhaustive, and in this case, an additional comment or explanation of the translator is needed: it is on Downing Street in London that the residence of the Prime Minister of the United Kingdom is located. The usual transliteration of the name of New York's Wallstreet (a symbol of business and financial America) in the absence of background knowledge does not convey any information.

As a result, it should be borne in mind that in the process of semantization of lexical units, both their lexical meanings and lexical background must be revealed. Therefore, the best way to semantize them is to comment in several ways: single, systemic, and comprehensive. A single comment explains the basic meaning of individual lexical units [444, c. 9]. For example, downtown is a business part of the city, or describing something located in the business part of the city; barbecue is meat and vegetables cooked on a grill over hot coals. The two lexical tokens have initially emerged in American English and induce associations with American culture, yet with time they have started being used in all other national variants of English and even more, have entered other languages representing typical US realia. The word barbecue is of Arawak (indigenous people inhabiting the Caribbean region) origin which went into English through Spanish barbacoa. Nevertheless, Australian English has developed an abbreviated form Barbie, the South African analogue is Braai (a term expressing emphasis on a family gathering, not so much on food prepared on a grill), and in the UK the usual form is truncated to $B B Q$. In light of the above, in these cases, a single comment is necessary for the communication to be effective.

A systemic commentary is used to semantize lexical items united by one common concept. This methodological technique is aimed at highlighting the general and specific features of the word that is semantized. For example, the name of the English holiday Pancake Day can be given next to Easter or Christmas, because the common concept for these words is "religious holidays": Pancake Day, also called Shrove 
Tuesday, is the traditional feast day before the start of Lent (the 40 days leading up to Easter) on Ash Wednesday.

A comprehensive commentary involves the semantization of thematic vocabulary. Thus, when studying the topic "Recreation and travel", the teacher ought to give a description of typical for the country types of recreation and travel, name favourite places for recreation and entertainment, identify the advantages and disadvantages of a particular mode of transport for travel and more. For better mastering of thematic vocabulary, such lexical units should be semantized at once together.

Cross-cultural communication, or also called intercultural communication, is an adequate mutual understanding of two participants in a communicative act belonging to different national cultures [446]. The desire for acquiring communicative competence as the end result of teaching a foreign language to students, regardless of their speciality, involves not only the possession of appropriate foreign language techniques (i.e., language competence of students) but also the acquisition of nonverbal information necessary for adequate communication and understanding. Therefore, the teaching of foreign languages at a stage when students have sufficient skills of reading, writing, listening and speaking, should be built as a study of the phenomenon of culture of the people who speak this language.

The formation of students' sociolinguistic competence as an essential component in the process of teaching English is the key to effective intercultural communication. An acquaintance of students with national and cultural features of the country whose language is studied helps to increase the educational role of foreign language teaching, as it allows to expand the horizons of students, to form and develop their interest in studying this subject, to raise their public consciousness. 